\title{
Refractive Error Prevalence among School Children in Dadeldhura District of Nepal Awasthi $\mathrm{S},{ }^{1,2}$ Pant $\mathrm{BP},{ }^{1}$ Langaas $\mathrm{T}^{2}$
}

${ }^{1}$ Geta Eye Hospital,

Geta, Kailali, Nepal.

${ }^{2}$ Department of Optometry,

Radiography and Lighting Design,

University of South-Eastern Norway

Kongsberg, Norway.

\section{Corresponding Author}

Suresh Awasthi

Geta Eye Hospital,

Geta, Kailali, Nepal.

E-mail: suresh.buc@gmail.com

\section{Citation}

Awasthi S, Pant BP, Langaas T. Refractive Error Prevalence among School Children in Dadeldhura District of Nepal. Kathmandu Univ Med J. Online First.

\section{ABSTRACT}

\section{Background}

Uncorrected refractive error is the major cause of visual impairment worldwide. There is no data on refractive error prevalence among school children in hilly region of Far West Nepal.

\section{Objective}

The prevalence of refractive error has been found to vary among children of different caste/ethnic groups and geographical regions. The purpose of this study is to determine the prevalence of refractive error among school children from different caste/ethnic groups in Dadeldhura district of Far West Nepal.

\section{Method}

This is a cross sectional study of refractive error among secondary school children from 2 schools in Dadeldhura district. All children underwent a vision screening consisting of visual acuity, ocular examination and refraction. Myopia was diagnosed for an eye with spherical equivalent refraction $(S E R) \leq-0.5 D$ whereas an eye with SER $\geq+2.0 \mathrm{D}$ was diagnosed as hyperopic. Ethnicity was reported through self administered questionnaire.

\section{Result}

Among children aged 12 to 16 years $(14.07 \pm 1.4)$ prevalence of myopia was $3.5 \%$, hyperopia $0.33 \%$ and astigmatism $1 \%$. All except three children had spherical equivalent refraction (SER) within $\pm 2 \quad \mathrm{D}$. Caste/ethnicity was not associated significantly with myopia in either eye $\left(\chi^{2}=0.27, d f=2, p=0.87\right)$.

\section{Conclusion}

The prevalence of refractive error among secondary school children in Dadeldhura district of Far West Nepal is very low in comparison to myopia prevalence reported in studies from other parts of the world, but slightly lower than myopia prevalence found in other, eastern parts of Nepal.

\section{KEY WORDS}

Far West, Refractive error, School children 


\section{INTRODUCTION}

The global prevalence of visual impairment due to uncorrected refractive error (defined as visual acuity improving to $6 / 18$ and better with spectacles or pinhole) is $0.97 \%$ (equal to 12.81 million) in children aged $5-15$ years. ${ }^{1}$ The burden of uncorrected refractive error is variously reported from $36.7 \%$ in Hongkong, $42.7 \%$ 65.3\% in China, $65.3 \%$ in Korea, $61 \%$ in Taiwan and $65.6 \%$ in Japan. ${ }^{2-6}$ Moderate prevalence rates varying from $21 \%$ to $34 \%$ have been observed in Norway, Germany and USA. ${ }^{7-9}$ There is a huge global loss (US\$ 202000 million) in gross domestic productdue to uncorrected refractive error. ${ }^{10}$

Indo Aryans, reported to have migrated from south and west of Nepal, had lower prevalence of myopia in comparison to Mangols who are reported to have migrated from north and east of Nepal. ${ }^{11,12}$ The prevalence of myopia is lower among public school children in comparison to private school children in Nepal and India possibly due to more reading at closer distance less than 30 centimeters and continuous reading for more than 30 minutes..$^{11,13-15}$ On the contrary, the CLEERE studies showed minor role of near work or outdoor/sports activity in myopia progression in contrast to studies that found outdoor activity to have major role. ${ }^{16-19}$

The purpose of this study was to determine the prevalence of refractive error among school children from Dadeldhura district where published data is not available on refractive errors. Prevalence data could be useful for planning refractive error services in this region.

\section{METHODS}

A cross sectional study on refractive errors and ethnicity was conducted among school children during July to Sept 2009. There were 9995 students in 42 secondary level schools (grade 6 to 10) in Dadeldhura district. ${ }^{20}$ Secondary schools in the district headquarter were divided into two groups or strata i.e. schools within the market area and schools away from the market area. From each stratum, one secondary level school was randomly selected. Children were invited to participate in the study through an information leaflet explaining nature, purpose and methods of the study. Children and their parents who gave written consent were included in the study. The study was approved by Nepal Health Research Council and was conducted following the tenets of Declaration of Helsinki.

Children were run through procedures divided into 5 test stations. At station 1, we collected parental consent and questionnaire forms on age, gender, age at school entrance, outdoor activities, parental occupation, parental spectacle use, parental education and ethnicity. ${ }^{17}$ In station 2 , each child underwent visual acuity assessment using a log MAR chart at $6 \mathrm{~m}$ distance and monocular amplitude of accommodation using a RAF ruler. The child was asked to identify orientation of the log MAR ' $E$ ' optotypes with each eye separately. The child was asked to continue to the next line, if at least 3 out of 5 optotypes of a line were identified. The log MAR value of the last line which could be identified correctly was recorded as visual acuity score. The children were observed throughout the procedure to prevent squinting (pinhole effect). If a child was wearing glasses, visual acuity was also assessed with habitual glasses.

Previous prescription and cover test was assessed at near and distance in station 3 . In station 4 , anterior segment evaluation with torch light and posterior segment evaluation with direct ophthalmoscope were performed. Retinoscopy followed by subjective refraction was performed to determine refractive error. Accommodation response was assessed by MEM retinosocopy in station 5 .

After completion of ophthalmic examination, the children were explained about the condition of their eyes in station 1. Written report/prescription was not given to participants as treatment was provided to those who required it by the study team. Children who could not respond accurately to visual acuity assessment, with history of ocular trauma, disease and surgery affecting vision were excluded from the study. Children requiring prescription were provided spectacles at no cost from Dadeldhura Eye Care Centre whereas those with ocular pathology were referred to the Geta Eye Hospital with a referral slip. Myopia was diagnosed for an eye with spherical equivalent refraction (SER) $\leq-0.5$ $D$ whereas an eye with SER $\geq+2.0 \mathrm{D}$ was diagnosed as hyperopic. A child was considered myopic if one or both eyes had myopia; hyperopic, if one or both eyes had hyperopia, provided there was no myopia in the other eye. Emmetropia was labeled if both eyes had neither myopia nor hypermetropia. ${ }^{21}$

The computer software PASW 17.0 was used for data analysis. The frequency, percentage and mean with standard deviations were used to describe variables. For comparison between age groups one way ANOVA and Independent sample t-test were used with significance level at $p<0.05$. Chi-square test was used to test independency among variables and to investigate any association between myopia and covariates.

\section{RESULTS}

Among 700 children who were examined, 590 aged 12 to 16 years (mean $=14.07 \pm 1.4$ years) were included in the study (table 1). Among children not included, 71 were below 12 years and above 16 years old, 4 had cataract surgery done and 5 had posterior segment abnormalities.(table 1)

There were 25 (4.23\%) children with uncorrected visual acuity of $0.2 \log$ MAR (6/12) and worse in one or both eyes. With correction, $9(1.52 \%)$ children had visual acuity of $0.2 \log$ MAR or worse in either eye, and 5 (0.84\%) children had reduced visual acuity to this level in both eyes (table 
Table 1. Age, gender and ethnicity wise distribution of children

\begin{tabular}{|c|c|c|c|}
\hline \multicolumn{2}{|l|}{ Groups } & No. (\%) of children & $\begin{array}{l}\text { No. (\%) of } \\
\text { Myopic Children }\end{array}$ \\
\hline \multirow{5}{*}{ Age } & 12 & $104(17.6)$ & $1(0.96)$ \\
\hline & 13 & $119(20.2)$ & $5(4.2)$ \\
\hline & 14 & $127(21.5)$ & $7(5.5)$ \\
\hline & 15 & $111(18.8)$ & $4(3.6)$ \\
\hline & 16 & 129 (21.9) & $4(3.1)$ \\
\hline \multirow{2}{*}{ Gender } & Male & $280(47.5)$ & $7(2.5)$ \\
\hline & Female & $310(52.5)$ & $14(4.5)$ \\
\hline \multirow{5}{*}{ Ethnicity } & Bahun & $156(26.4)$ & $6(3.84)$ \\
\hline & Chhetri & $290(49.1)$ & $9(3.1)$ \\
\hline & Dalit & $126(21.3)$ & $5(4)$ \\
\hline & Mangol & $17(2.8)$ & $1(5.88)$ \\
\hline & Others & $1(0.1)$ & 0 \\
\hline \multicolumn{2}{|l|}{ Total } & $590(100)$ & $21(3.56)$ \\
\hline
\end{tabular}

2). Although 36 children reported using spectacles, only 2 had spectacles during ophthalmic examination. Others reported that they had spectacles at home; the spectacles were broken or lost. (Table 2)

Table 2. Distribution of Uncorrected and Corrected Visual Acuity

\begin{tabular}{lll|}
\hline Visual Acuity & $\begin{array}{l}\text { No. (\%) of Children } \\
\text { with Uncorrected } \\
\text { Visual Acuity }\end{array}$ & $\begin{array}{l}\text { No. (\%) of Children } \\
\text { with Corrected } \\
\text { Visual Acuity }\end{array}$ \\
\hline$\geq 0.2$ both eyes & $565(95.8)$ & $581(98.5)$ \\
$\geq 0.2$ one eye & $9(1.5)$ & $4(0.68)$ \\
$\leq 0.3$ to $\geq 0.5$ in & $12(2.0)$ & $4(0.68)$ \\
better eye & & $1(0.16)$ \\
$\leq 0.6$ to $\geq 1.0$ in & $4(0.68)$ & \\
better eye & & $590(100)$ \\
\hline Total & $590(100)$ &
\end{tabular}

The SER values ranged from -2.25 to $+3 \mathrm{D}(+0.01 \pm 0.24$ D) in right eye and -3.5 to $+4.0 \mathrm{D}(+0.008 \pm 0.29 \mathrm{D})$ in left eye. All children except three had SER values within \pm 2 D. When comparing age groups, 14 year olds (right eye= $-0.02 \pm 0.30 \mathrm{D}$, left eye $=-0.04 \pm 0.39 \mathrm{D})$ had the most myopic mean SER. For the population as a whole, the prevalence of myopia was $3.5 \%(n=21)$, hyperopia $0.33 \%$ $(n=2)$ and astigmatism 1\% (6 of 590). Refractive error was not significantly different between children aged less than 14 years and children aged 14 and more $\left(\chi^{2}=0.78\right.$, df $=1$, $p=0.37)$. There was no significant association between spherical equivalent refraction and gender $\left(\chi^{2}=1.7, \mathrm{df}=1\right.$, $p=0.18$ ) or caste/ethnic groups $\left(\chi^{2}=0.27, d f=2, p=0.87\right)$. Among caste/ethnic groups, Chhetri had the highest (9 out of 299 children) and Mangols had the least number of myopic children ( 1 out of 18 children).

The correlation between mean outdoor activity during weekdays ( $2.6 \pm 1.6$ hours) and SER was tested but was found not to be significantly related in right $(r=-0.029, p=$ $0.49)$ and in left eye $(r=0.044, p=0.29)$ respectively. The mean accommodative response in right eye was $+0.99 \pm$ $0.34 \mathrm{D}$ and in left eye it was $+1.02 \pm 0.37 \mathrm{D}$. The SER and accommodative response were significantly correlated in right eye $(r=0.19, p<0.05)$ whereas significant correlation was not observed in left eye $(r=0.074, p=0.074)$.

Among parents who attended at least one year of formal school, 3.4\% (16 of 466) had myopic children whereas among parents who never attended school 4.8\% (5 of 105) had myopic children. Among fathers engaged in agriculture/household activities, 3.9\% (10 of 257) had myopic children whereas among fathers engaged in other occupations 3\% (9 of 300) had myopic children. Among either parent using spectacles, $6.2 \%$ (8 of 129) had myopic children whereas among parents not using spectacles $2.8 \%$ (13 of 461) had myopic children. Parental education (higher of the two parents) and father's occupation and father's spectacle use were not significantly associated with myopia in right eye, left eye and either eye. Among mothers engaged in agriculture/household activities, 3.2\% (17 of 535) had myopic children whereas among mothers engaged in other occupations $8.6 \%$ (3 of 35) had myopic children. The association between spectacle use by mother and myopia in either eye $\left(\chi^{2}=4.05, d f=1, p=0.044\right)$ was significant though not significant associations found for right eye and left eye.

\section{DISCUSSION}

In this study we measured refractive error and associated factors among secondary school children aged 12 - 16 years from Dadeldhura district of Far West Nepal. This is the first study on refractive error in this district. All children of selected schools were invited for the study. Of the total children invited for the study $81.5 \%$ were examined which was comparable to other studies. ${ }^{22,23}$

Of those children who reported that they used glasses, most of them were not wearing them during the eye examination: This may indicate that children do not use them regularly, which may be because they could see equally well without wearing their prescription due to low degree of refractive error. Supporting results were reported from China where more than $50 \%$ of school children wear spectacles only when needed or on special occasions. ${ }^{22}$

The proportion of children with reduced vision was low and was largely due to refractive error (16 out of 25). Our findings were slightly lower than found in eastern Nepal where among 138 children with reduced vision, 128 were due to uncorrected refractive error. ${ }^{24}$ Children who could not see properly to read and write might not attend school. They are more likely to be hyperopic as children face difficulty for near tasks. In this study only 2 children were hyperopic. The prevalence of myopia, 3.5\% was slightly higher than that reported from Jhapa, 1.2\% 24 and Solukhumbu, 2.9\% districts of eastern Nepal. ${ }^{25}$ The difference may possibly be due to various age range included in Solukhumbu (7- 
18 years) and Jhapa district (5-15 years). In recent study, higher prevalence of refractive error (8.6\%) was reported among school children of Jhapa district suggesting higher estimates present among younger generation of cohorts. ${ }^{26}$ Commonality between the current study and studies among children in eastern Nepal is the rural environment.

The prevalence of myopia among caste/ethnic groups was comparable except for the Mangol group for which comparison was difficult due to their low number in the study population. The prevalence estimates were higher in Kathmandu where large proportion of the population is of Mangol origin. ${ }^{11,13}$ It is reported that Aryans migrated from central Asian steppe through west and south boarder and Mangols migrated from Yunan plateau through east and north boarders of Nepal long time back in various stages. ${ }^{12}$ Our findings of lower prevalence of myopia is supportive for earlier studies, in Jhapa and Kanchanpur district where majority of the population were of IndoAryan origin..$^{24,27}$

The effect of sharing common environment among people of different caste/ethnic groups might possibly resulted in prevalence estimates among Bahun (3.84\%) and Chhetri (3.1\%) to be similar. Supporting this finding myopia prevalence was similar among Bahun $(8.03 \%)$ and Chhetri (9.45\%) ethnic groups in Pokhara city. ${ }^{28}$ However, a study among Mangol school children found lower prevalence of myopia among Sherpa children from public school in rural Solukhumbu in comparison to Tibetan children from private school in urban Kathmandu. Sherpa live mostly in Solukhumbu district of eastern Nepal whereas Tibetan moved to Nepal recently from Tibet. Sherpa and Tibetan children share common Mangol ancestry in Kham region of eastern Tibet. ${ }^{25,29}$ On the other hand Uyghur ethnic group had lowest prevalence of myopia (13\%) in comparison to Han (27\%) and Hui (18\%) possibly because Uyghur had genetic contribution from European ancestry. ${ }^{23}$ Contrary to this, lower prevalence was found among Indian children i.e. $8 \%$ for population based estimates and $10.8 \%$ for school based studies. ${ }^{30}$

The urban environment with more near work among Tibetan children from Kathmandu may be responsible for higher prevalence in comparison to Sherpa children from rural Solukhumbu where school work is not so strict. On the other hand similarity in myopia prevalence among rural Sherpa children with Mangol origin and children from rural Jhapa district with IndoAryan origin suggests the role of rural environment and less rigorous educational system in myopia. Myopia among children from China (36.9\%) was associated significantly with urban region. ${ }^{3}$ The study included public schools where children attend 1 year of preschool whereas in private schools where prevalence of myopia is higher, children attend 3 years of structured preschool. Children from private schools are likely to spend more time reading and less time on outdoor activities whereas children from public schools are likely to spend less time reading and more time in outdoor activities progression. It has been shown in studies that spending more time on outdoor activities protects against the development of myopia possibly due to more daily outdoor light exposure. ${ }^{17,18,19}$ Investigations on the possible factors contributing to the progression of myopia in different areas and ethnicities of the world are extensive and continuously ongoing, The aetiologi of refractive errors are likely to be multifactorial with both genetic and environmental components. In a study conducted in Southeast Norway, with a northen latitude and large seasonal variation of daylight exposure, adolescents were found to be mostly hyperopic and had low levels of myopia, despite high academic demands and near work activities.

It is suggested there may be different genetic predispositions to myopia in different ethnicities. ${ }^{31}$

These findings could guide clinicians for organizing school screening camps in the future. We would like to recommend to the government and nongovernmental organizations working in eye care to organize screening camps with refraction and prescription glasses to prevent further deterioration of vision and associated complications of refractive errors.

There are some limitations of the study. Children with latent hyperopia could have been misdiagnosed as emmetropic leaving fewer children in the hyperopia group caused by active accommodation during retinoscopy. As cycloplegic refraction was not done variations in refractive error could have affected our results. Although we planned to perform cycloplegic refraction initially it was discontinued as children did not agree to it. Also, a less strict inclusion criteria of hyperopia would increase the prevalence of hyperopia, although the finding of moderate to high hyperopia was low. In this study if $\leq-0.25 D$ was taken to define myopia, the prevalence of myopia would increase by 2.5 times in right eyes and 3 times in left eyes in comparison to the standard definition of $\leq-0.5 \mathrm{D}$. In another study, the prevalence of myopia more than doubled with the definition of $\leq-0.25 \mathrm{D}$ in comparison to the definition of $\leq-0.5$ D. ${ }^{25}$ Another limitation in this study was the small sample. With larger sample size, the prevalence estimates would have been more representative of the school age population in the district. Small proportion of Mangol population in this study could have affected comparison between Indo Aryan and Mangol groups.

\section{CONCLUSION}

From this study, we conclude that the prevalence of refractive error among secondary school children from Dadeldhura district was low and myopia was the commonest type of refractive error, 3.5\%. Myopia was not significantly associated with age, gender and caste/ethnicity. 


\section{ACKNOWLEDGEMENT}

We would like to thank Ms. Sahar Sandvik, Ms. Idun Nygard Egeli, Mr. Ole Enderson, Mr. Bård Helsa, Mr. Tor Martin Kvikstad, Dr. Per Lundmark and Mr. Mahesh Raj Joshi from University of South Eastern Norway and Mr. Om Pant, Ms.
Batti Gurung, Mr. Kishor Bhattarai and Mr. Jeewanand Bista from Geta Eye Hospital for supporting in data collection and manuscript preparation. We also thank principals, Mr T. Joshi, Mr. Prem Bohara and Mr. Siddha Raj Joshi for providing space in their schools for data collection.

\section{REFERENCES}

1. Resnikoff S, Pascolini D, Mariotti SP, Pokharel GP. Global magnitude of visual impairment caused by uncorrected refractive errors in 2004. Bulletin of the World Health Organization. 2008;86:63-70.

2. Fan DS, Lam DS, Lam RF, Lau JT, Chong KS, Cheung EY, Lai RY, Chew SJ. Prevalence, incidence, and progression of myopia of school children in Hong Kong. Investigative ophthalmology \& visual science. $2004 \mathrm{Apr}$ 1;45(4):1071-5

3. Wu JF, Bi HS, Wang SM, Hu YY, Wu H, Sun W, Lu TL, Wang XR, Jonas JB. Refractive error, visual acuity and causes of vision loss in children in Shandong, China. The Shandong Children Eye Study. PloS one. 2013 Dec 23;8(12):e82763.

4. Rim TH, Kim SH, Lim KH, Choi M, Kim HY, Baek SH. Refractive errors in Koreans: the Korea National Health and nutrition examination survey 2008-2012. Korean Journal of Ophthalmology. 2016 Jun 1;30(3): 21424.

5. Lin LL, Shih YF, Hsiao CK, Chen CJ. Prevalence of myopia in Taiwanese schoolchildren: 1983 to 2000. Annals-Academy of Medicine Singapore. 2004 Jan 1;33(1):27-33.

6. Matsumura $\mathrm{H}$, Hirai $\mathrm{H}$. Prevalence of myopia and refractive changes in students from 3 to 17 years of age. Survey of ophthalmology. 1999 Oct 1;44:S109-15.

7. Falkenberg HK, Langaas T, Svarverud E. Vision status of children aged 7-15 years referred from school vision screening in Norway during 2003-13: A retrospective study. BMC ophthalmology. 2019 Dec $1 ; 19(1): 180$.

8. Jobke $S$, Kasten $E$, Vorwerk $C$. The prevalence rates of refractive errors among children, adolescents, and adults in Germany. Clinical ophthalmology (Auckland, NZ). 2008 Sep;2(3):601.

9. Vitale S, Sperduto RD, Ferris FL. Increased prevalence of myopia in the United States between 1971-1972 and 1999-2004. Archives of ophthalmology. 2009 Dec 14;127(12):1632-9.

10. Fricke TR, Holden BA, Wilson DA, Schlenther G, Naidoo KS, Resnikoff S, Frick KD. Global cost of correcting vision impairment from uncorrected refractive error. Bulletin of the World Health Organization. 2012;90:728-38.

11. Sapkota YD, Adhikari BN, Pokharel GP, Poudyal BK, Ellwein LB. The prevalence of visual impairment in school children of upper-middle socioeconomic status in Kathmandu. Ophthalmic epidemiology. 2008 Jan 1;15(1):17-23.

12. Gurung $\mathrm{H}$, Kathmandu N. Physical and cultural patterns in the Himalaya. In Ponencia presentada en el International Seminar on Mountains, Katmandu 2002 Mar 6. http://www.himalayanvoices. org/sites/default/files/physical\%20and\%20cultural\%20patterns.pdf (assessed 13 October 2019)

13. Nepal BP, Koirala S, Adhikary S, Sharma AK. Ocular morbidity in school children in Kathmandu. British journal of ophthalmology. 2003 May 1;87(5):531-4.

14. Saxena R, Vashist P, Tandon R, Pandey RM, Bhardawaj A, Menon V, Mani K. Prevalence of myopia and its risk factors in urban school children in Delhi: the North India Myopia Study (NIM Study). PloS one. 2015 Feb 26;10(2):e0117349.
15. Ip JM, Saw SM, Rose KA, Morgan IG, Kifley A, Wang JJ, Mitchell P. Role of near work in myopia: findings in a sample of Australian school children. Investigative ophthalmology \& visual science. 2008 Jul 1;49(7):2903-10.

16. Jones-Jordan LA, Sinnott LT, Graham ND, Cotter SA, Kleinstein RN, Manny RE, et al. The contributions of near work and outdoor activity to the correlation between siblings in the Collaborative Longitudinal Evaluation of Ethnicity and Refractive Error (CLEERE) Study. Investigative ophthalmology \& visual science. 2014;55(10):6333-9.

17. Rose KA, Morgan IG, Smith W, Burlutsky G, Mitchell P, Saw SM. Myopia, lifestyle, and schooling in students of Chinese ethnicity in Singapore and Sydney. Archives of ophthalmology. 2008 Apr 1;126(4):527-30.

18. Jin JX, Hua WJ, Jiang X, Wu XY, Yang JW, Gao GP, et al. Effect of outdoor activity on myopia onset and progression in school-aged children in northeast China: the Sujiatun Eye Care Study. BMC ophthalmology. 2015 Dec 1;15(1):73.

19. Read SA, Vincent SJ, Tan CS, Ngo C, Collins MJ, Saw SM. Patterns of daily outdoor light exposure in Australian and Singaporean children. Translational vision science \& technology. 2018 May 1;7(3):8.

20. Nepal, G. O. School Level Educational Statistics of Nepal Consolidated Report 2006. D. o. Education. Kathmandu, Department of Education; 2007. https://books.google.com.np/books/about/School_Level_ Educational_Statistics_of_N.html?id=JNICLCFwKewC\&redir_esc $=\bar{y}$ (assessed 14 October 2019)

21. Negrel AD, Maul E, Pokharel GP, Zhao J, Ellwein LB. Refractive error study in children: sampling and measurement methods for a multicountry survey. American journal of ophthalmology. $2000 \mathrm{Apr}$ 1;129(4):421-6.

22. Congdon $N$, Zheng $M$, Sharma A, Choi K, Song $Y$, Zhang $M$, et al. Prevalence and determinants of spectacle nonwear among rural Chinese secondary schoolchildren: the Xichang Pediatric Refractive Error Study Report 3. Archives of ophthalmology. 2008 Dec 8;126(12):1717-23

23. Chin MP, Siong KH, Chan KH, Do CW, Chan HH, Cheong AM. Prevalence of visual impairment and refractive errors among different ethnic groups in schoolchildren in T urpan, $\mathrm{C}$ hina. Ophthalmic and physiological optics. 2015 May;35(3):263-70.

24. Pokharel GP, Negrel AD, Munoz SR, Ellwein LB. Refractive error study in children: results from Mechi Zone, Nepal. American journal of ophthalmology. 2000 Apr 1;129(4):436-44.

25. Garner LF, Owens H, Kinnear RF, Frith MJ. Prevalence of myopia in Sherpa and Tibetan children in Nepal. Optometry and vision science: official publication of the American Academy of Optometry. 1999 May;76(5):282-5.

26. Shrestha GS, Sujakhu D, Joshi P. Refractive error among schoo children in Jhapa, Nepal. Journal of Optometry. 2011 Apr 1;4(2):4955.

27. Awasthi S, Pant BP, Dhakal HP. Reduced Vision and Refractive Errors, Results from a School Vision Screening Program in Kanchanpur district of Far Western Nepal. Kathmandu University Medical Journal. 2010;8(4):370-4. 
28. Niroula DR, Saha CG. Study on the refractive errors of school going children of Pokhara city in Nepal. Kathmandu University Medical Journal. 2009;7(1):67-72.

29. Eley G, Ortner SB. High religion: A cultural and political history of Sherpa Buddhism. Princeton University Press; 1989. https://books. google.com.np/books?hl=en\&lr=\&id=PeM9DwAAQBAJ\&oi=fnd\&pg $=$ PR11\&dq=29.\%09Eley+G,+Ortner+SB.+High+religion:+A+cultural+ and+political+history+of+Sherpa+Buddhism.+Prn+University+Press \%3B+1989+Sep+21.\&ots=tp1aJboU3I\&sig=T3M60EYsgEg0estuFI7w_ b3D4d4\&redir_esc=y\#v=onepage\&q\&f=false (assessed 14 October 2019).
30. Sheeladevi S, Seelam B, Nukella PB, Modi A, Ali R, Keay L. Prevalence of refractive errors in children in India: a systematic review. Clinical and Experimental Optometry. $2018 \mathrm{Jul} ; 101(4): 495-503$.

31. Hagen LA, Gjelle JV, Arnegard S, Pedersen HR, Gilson SJ, Baraas RC. Prevalence and possible factors of myopia in Norwegian adolescents. Scientific reports. 2018 Sep 7;8(1):1-0. 